\title{
Festschrift in Honor of Professor Margaret Anne Knowles
}

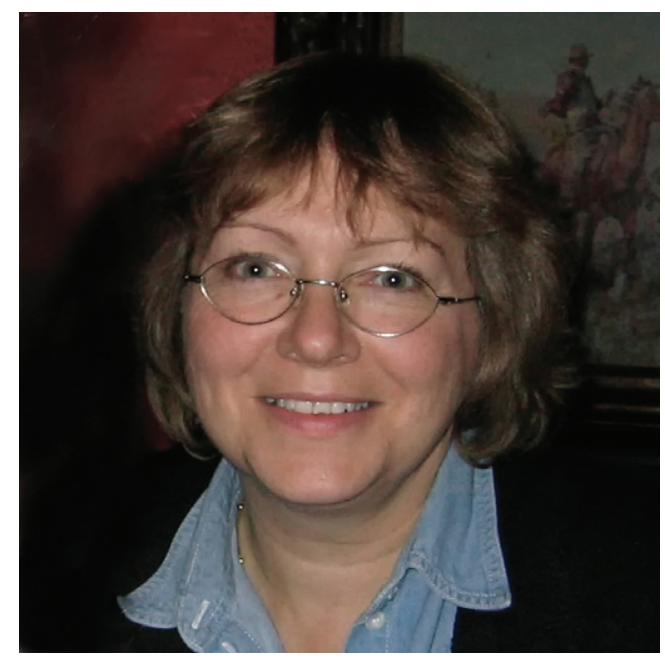

Professor Maggie Knowles.

Received 17 August 2020

Accepted 16 September 2020

Pre-press 8 October 2020

Published 14 December 2020

\section{INTRODUCTION}

\section{Professor Ellen Zwarthoff PhD, Department of Pathology at Erasmus MC, Rotterdam, The Netherlands}

It is a great pleasure to contribute to this Festschrift in honor of Professor Margaret Anne Knowles, better known to all bladder cancer aficionados simply as Maggie. Maggie has been working on bladder cancer since she obtained her $\mathrm{PhD}$. Her first bladder publication was on organ culture of the human bladder and appeared in 1980. Maggie and I are the same age with only a month between us and it appeared we did our PhDs both in the late nineteen seventies. However, after that I wandered around for a long time before setting my eye on bladder cancer genetics as a major subject, whilst Maggie stuck with the bladder ever since. From 1990 till recently, Maggie spent a lot of time trying to pinpoint tumor suppressor genes on chromosome 9 because loss of the entire chromosome or large deletions on both the $\mathrm{p}$ and especially the $\mathrm{q}$ arm are so common in bladder tumors. She characterized the inactivating mutations in TSC1 on 9q and the deletions in CDKN2A on 9p. However, there was no gene that really met the criterion for being THE tumor suppressor gene on this chromosome such as $R B$ or TP53. I know, because we were trying to find this elusive gene ourselves. The 2017 Cancer Cell paper from Maggie and Carolyn (her second in command and anchor) provides evidence that this gene may not exist and Maggie and Carolyn suggested that haploinsuffiency for multiple chromosome $9 \mathrm{q}$ genes may be important for bladder cancer tumorigenesis. Hopefully someone will once come up with the solution to this multidimensional puzzle. 
Maggie and I first met at the 2000 AACR meeting in San Francisco as she also mentions in her contribution to my Festschrift. I remember being very impressed by her knowledge and awareness of our, not so many, bladder cancer publications at that time. This illustrates her thoroughness and as everybody knows this is also evident in her many in-depth reviews in particular on the genomic changes in bladder cancers. I think these were a magnificent contribution to the field and helped many of us to keep up with the rapid developments in the recent 2 decades. Her lab published a multitude of papers on FGFR3 mutations and the PIK3CA pathway in bladder cancer and so on. She was the first to describe that FGFR3 could also be activated by gene fusion. Moreover, she was one of the first to investigate the possible therapeutic consequences of activating mutations in FGFR3 and PIK3CA.

Since 2000 we met many many times at meetings (AACR, EUA, ESUR, IBCN etc.). Dear Maggie, I think at all these meetings we found one another, had a glass (or more) of white wine and discussed our projects and students and families and politics and funding and holidays in France. The bladder dinners were always hilarious and funny. I remember one, I think in Orlando or perhaps Chicago, where our students ordered entrees and main dishes and desserts, whereas we as group leaders (Maggie, Torben, Arndt and so on) were far more frugal and worried about the costs. Thank you also for coming to Rotterdam as a member of the $\mathrm{PhD}$ defense committees of Angela, Tahlita and Kim.

Dear Maggie, I wish you all the best after your decades long fantastic contributions to science. Do enjoy your retirement together with David, your family and friends.

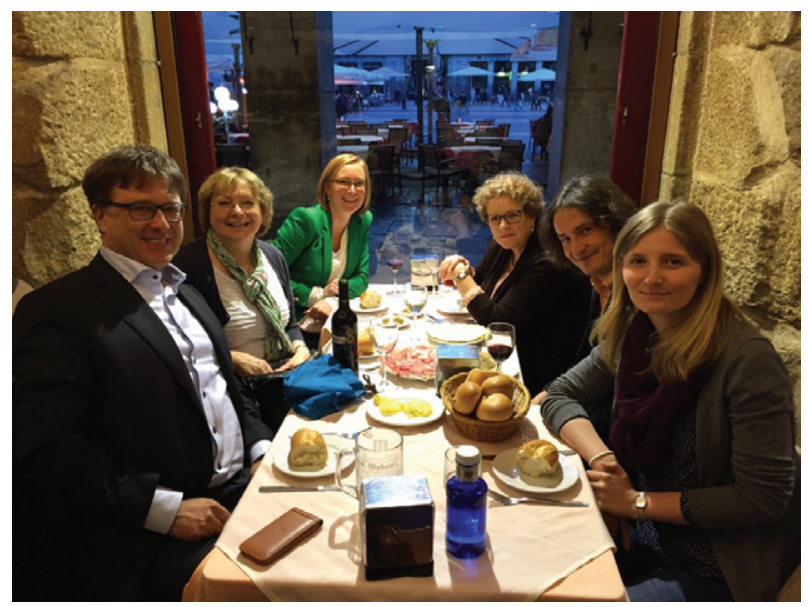

Bladder dinner in Madrid (EAU 2015). From left to right: Arndt Hartmann, Maggie Knowles, Kim van Kessel, Ellen Zwarthoff, Ralph Wirtz, Veronika Weyerer.

\section{Prof D Timothy Bishop, long-term colleague and friend at the University of Leeds}

I first met Maggie in 1996 when she interviewed for the post of Deputy Director in the Imperial Cancer Research Fund Cancer Centre at St James's Hospital, University of Leeds, U.K.. This was a memorable event because of the importance of making the right appointment at that time but made more memorable by the need to complete the interviews outside in the car park because of a persistent fire alarm. At that stage, while looking forward to having a well-respected colleague to lead the Centre's laboratory oncology research, I am sure I did not realise the significance of the appointment to my research and indeed to my subsequent academic life. Initially, the alignment of our research groups working on the genomics of a solid tumour (Maggie, of course, on bladder; our group on melanoma) was simply pleasing and a happy coincidence especially as our group lacked some of the expertise that Maggie brought. However, over the years, our science developed along parallel lines through technologies and methodologies (large-scale SNP genotyping, somatic mutation detection, copy number changes, histopathology, bioinformatics) and so there has always been positive reasons for a constant dialogue between us and between our groups.

Academic life, of course, is only to a limited extent about having colleagues with similar scientific endeavours. Interactions with Maggie have always been more than that. She has brought academic excellence and precision, 
together with complete integrity plus being also a willing and thoughtful listener. She has always been adept at producing the "two sides of A4" to make a case or to outline strategy (while grumbling, but not convincingly). Between us, we have over the years been able to develop resources to Leeds such as bringing Cancer Research UK Research Services of genotyping and mutation detection which was beneficial for our own research while ensuring support and facilities for colleagues across the UK. As we became more senior and had to take on more responsibilities for the Institute, the importance of having calm, thoughtful, responsive and responsible colleagues such as Maggie is beyond doubt. While Maggie has never put herself forward, she has always been a constant supporter, the type of colleague critical to any Institution.

It is clearly often true that within academic institutions, a person's international standing is not readily apparent and especially when a person's natural inclination is to focus on their own science. I have heard Maggie speak at AACR in the USA on several occasions and have wondered how many colleagues back in Leeds recognise her status within her field. Others within that field will comment in this Festschrift document of the impact of her work and the insights she has produced. I can only comment as a long-term colleague and friend about the other aspects, her supportiveness, her scientific acumen, her respect for others and her focus on science, especially cancer science, making sure that the right questions were being asked and were being answered. Thank you, Maggie, it's been a memorable time.

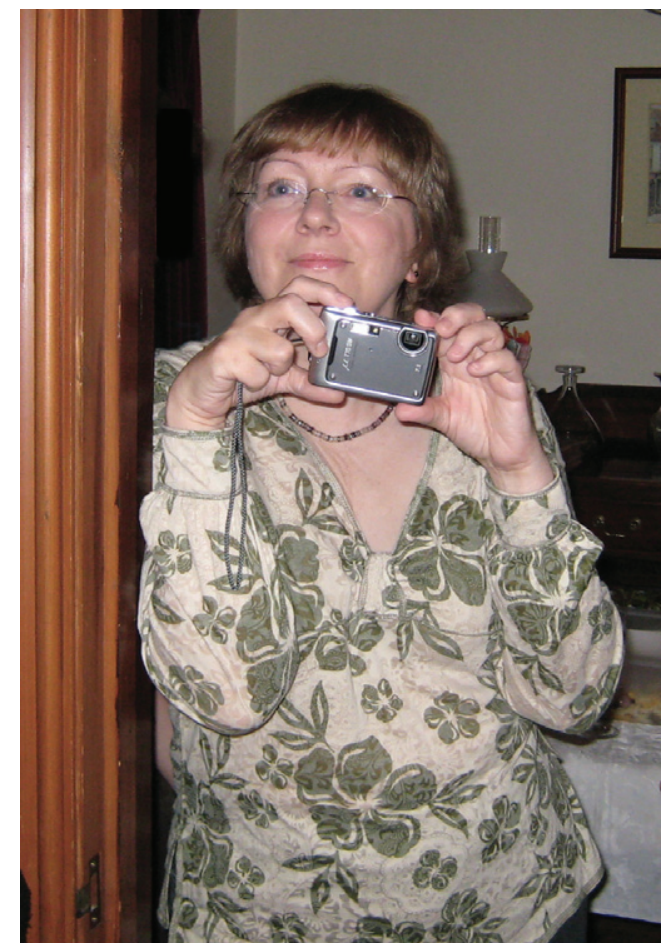

Maggie photographed at a group social event in Leeds, UK (2000).

Professor Peter Selby, MD DSc, Emeritus Professor, Leeds Institute of Medical Research at St James's, University of Leeds, Leeds, UK

Thank you very much for the opportunity to write something on the career and retirement of Professor Maggie Knowles. We were colleagues for over 20 years in the Cancer Research Unit at Leeds and shared the leadership responsibilities there. We in fact had met some years earlier when I spent a short sabbatical in the Marie Curie Research Institute in Surrey where she was a Group Leader. I remember being very impressed at the time by the quality and focus of her science. Later in 1997 Maggie joined us in Leeds and together with Professor Tim Bishop we developed research activities in the University and NHS there. The Unit grew to a substantial size and had basic science, epidemiology and clinical groups. We developed an interdisciplinary and collegiate leadership style in which the three of us met most Mondays to talk about what was happening in the Unit and how we 
could take it forward. We sought to cultivate interdisciplinary research (perhaps a little before it became so very fashionable) and there is some reasonable evidence that we succeeded much of the time.

Maggie contributed many things. First and foremost she was an excellent cell and molecular biologist, molecular geneticist and cancer scientist. Her focus upon understanding the mechanisms underpinning epithelial malignancies was awesome. It provided a model of excellent focused science for all of our Unit's members and presented our clinician scientists and scientific clinicians with a model to admire and an insight into the way in which the best of focused science is delivered. The best way I can illustrate this is to trace Maggie's publication record. She wrote a seminal paper in Cancer Research in 1977 on neoplastic transformation in adult epithelial cells following carcinogen exposure with Sammy Franks which deployed a range of the then available, innovative technologies to study the stages of neoplastic transformation. This was followed by a steady flow of high-quality papers using state-of-the-art technologies including electron microscopy and the development of biological markers for neoplastic change which are still relevant today. Fast forward to 2017 and in Cancer Cell, Maggie and her colleagues are describing the genomic sub-types of non-invasive bladder cancer in patients with fresh insights into the genetic basis of the disease and its metabolic and biological profile. Her most impressive portfolio of research retained focus on an important question of great clinical relevance, consistently deployed a range of state-of-the-art technologies and invented some new ones, to answer the key question. Second, Maggie always retained an eye to the potential for clinical applications of her work. She had a translational aspect to her work well before it became a requirement from funding bodies. The applications of her characterisation of superficial bladder cancer to enhance our understanding of its clinical biology allow us to design better schedules for the management and follow up and treatment of patients. They continue to be exploited by Pathologists and Urological Surgeons. Third, she is a great collaborator. You will hear from others her contributions to large and influential international collaborations to help understand the genetics and biology of bladder cancer. I can provide a more domestic perspective. In our Cancer Research Centre in Leeds we had clinicians of all kinds, clinician scientists, pathologists and clinical biochemists working on many aspects of urological cancers. They would often turn something up in their explorations of the clinical challenges and clinical materials. So if a 2D-gel or a mass spectrometer turned up a spot or a peak that seemed to have something to do with the behaviour of the cancer in question, invariably Maggie was able to provide advice, insights and scientific inputs that moved the work forward and added a basic and mechanistic insight to sit alongside the clinical and pathological findings. Her joint publications with Roz Banks, Naveen Vasudev and me reflect many formal and informal inputs to ensure the science was of high quality. She is a great team leader and that team has often involved clinician scientists. Jackie Adams, John Chester, Adel Samson and others were working for their PhDs or developing their translational research credentials under Maggie's scientific oversight.

Maggie's input into the development of cancer research in Leeds and its leadership was comprehensive and outstanding. The consistent quality of her science added to her collaborative approaches made many things possible. I will always be grateful to her for allowing me to knock on her door and pick her brains when a particular challenge, scientific or organisational, needed some discussion. She was always generous with her time even though I am sure her heart sank when she knew that another hour's "group therapy" was necessary to take forward a project or sort out the troubles of one of our members of staff. Our work together at the clinical/laboratory scientific interface was great fun and productive and it was a joy to work with her on the fourth edition of An Introduction to the Cellular and Molecular Biology of Cancer continuing that publication which she had begun with Sammy Franks in the earlier days of the Imperial Cancer Research Fund.

I am sure that Maggie will continue to be very involved and active in science and the scientific community as an Emeritus Professor and I am honoured to have the opportunity to thank her and congratulate her on all of her achievements and contributions.

\section{Dr Carolyn Hurst, PhD, Leeds Institute of Medical Research at St James's, University of Leeds, Leeds, UK}

I joined Maggie's group as a post-doctoral research fellow in 2001 with a good set of molecular biology skills but very little knowledge of bladder cancer. It was a steep learning curve at the start but in Maggie I had the very best of PIs and mentors, and within her group I had the very best and friendliest of working environments. Since 2001 we have worked together on many different projects, moving as the technology has advanced from 
studying mutations in single genes to carrying out genome-wide analyses. It has been a wonderful journey and I have loved every minute of it.

It has been said by so many people (myself included) that Maggie's door is always open and she is always available to whoever pokes their head around it. In recent years, Maggie very rarely had any free time to work in the lab but this never stopped her from showing her excitement whenever I or a fellow group member appeared in her office with a pleasing result. This excitement was usually quickly followed by an enthusiastic "What's next?". I have always found this enthusiasm for science truly infectious and very often left Maggie's office smiling and excited by the prospect of what was next. Her knowledge of bladder cancer, molecular biology, cell biology and genetics is immense and she has always willingly shared this knowledge and collaborated readily with others. Maggie is a great communicator of science and I have been lucky enough to co-author a number of publications with her and to see her talk on a number of occasions. I have very happy memories of the fun and exhausting AACR conferences we attended together. The choice of shoes was always critical to successfully getting from one end of the convention centre to the other in time for the next session, and the day always ended with a nice relaxing glass of wine and an enthusiastic discussion of the science.

Maggie, it has been a real pleasure and a privilege to have been part of your group for over 19 years. You have been a wonderful mentor and have helped me grow as a scientist, as a mentor to others and as a person. This is a new era for both of us but I will never forget how you have supported and guided me. Thank you from the bottom of my heart. Enjoy your new role as Emeritus Professor and spend many fun-filled hours with your grandchildren.

Dr Darren Tomlinson, PhD, Astbury Center for Structural and Molecular Biology, University of Leeds, Leeds, $U K$

I'm really happy to have been asked to write my personal thoughts about Maggie. I first met Maggie when she interviewed me for a CRUK funded post-doctoral position in her laboratory. I had just finished my $\mathrm{PhD}$ in developmental biology at Edinburgh University and somehow managed to wrangle an interview and I got the post. At that point I had very little experience in genetics, pathology or even cancer biology but Maggie gave me a chance and I started working in her lab in 2002. Little did she realize I would be working with her for the next 8 years! I initially started working on looking at mutation frequency and expression levels of FGFR3 and their association with grade and stage. We moved into studying the function of FGFR3 in bladder cells and soon discovered changes in FGFR3 isoform expression and other FGF receptors. Our work moved away from genetics and towards cell biology to understand the function of mutations and expression in a cellular context with funding from AICR and YCR before I moved on to starting my own group.

Maggie has always been an exceptional PI and supervisor and provided a wealth of support during my time as a post-doc. Her door was always open and she was always happy to talk and discuss about science. Maggie's consistent patience, understanding and scientific knowledge really encouraged and nurtured my excitement for science. I had some of the best times in my working career while being supervised by Maggie, which had a major influence on my career choice. It's very sad to see Maggie retiring and it will be a great loss to the bladder field where she'll be greatly missed. However, I'm sure Maggie will be very happy pottering in her greenhouse and garden and looking after her grandchildren.

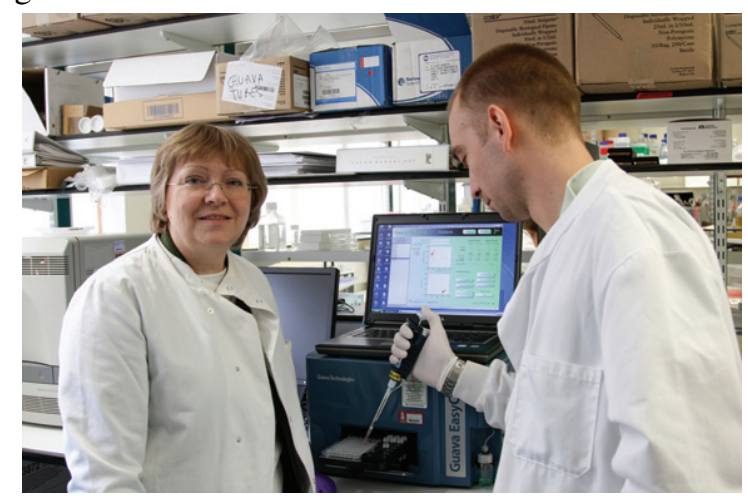

Maggie with postdoctoral research fellow Darren Tomlinson in the lab at St. James's University Hospital, Leeds, UK (2009). 


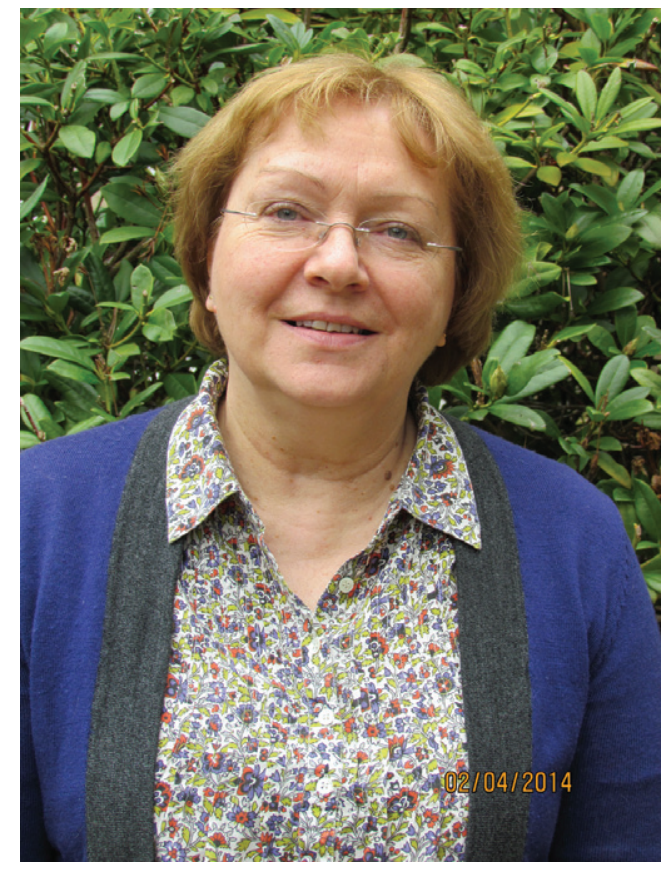

Maggie at the Yorkshire Cancer Research Award Holders Meeting held in Harrogate, West Yorkshire, UK (2014).

\section{Dr Emma Chapman, PhD, Leeds Institute of Health Sciences, University of Leeds, Leeds, UK}

As my PhD supervisor, Maggie provided an excellent role model which has positively influenced how I interact with my colleagues and students. Her research group was a friendly, supportive environment, where long-term friendships were often formed. It was a privilege to work in a lab where everyone's work was considered important and no-one too important to help out with more routine tasks. Maggie operated an "open door" policy which meant that she was always available to share in research successes (small or big), answer quick questions and also commiserate or advise when things were not going to plan. This approach installed a confidence in her students to try ambitious experiments and a resilience to move on from the occasional but inevitable difficulties with research.

Maggie has a great enthusiasm for Science and for how we can best translate the knowledge gained into patient benefit. This enthusiasm was apparent, on the occasions when she was called to don her (very clean) lab coat and venture into the Tissue Culture lab. Here she would excitedly discuss our latest cultures of cells and her encyclopaedic knowledge of bladder cancer cell lines, their genetics and culture preferences would be apparent.

I would like to thank Maggie for such a positive start to my research career and I wish her all the best for her retirement.

\section{James WF Catto, University of Sheffield, Editor European Urology}

Few readers of this journal will need an introduction to Margaret Knowles. For more that 40 years, Maggie has been at the cutting edge of cancer research, focusing most of her attention on the search for drivers of Urothelial Carcinogenesis and the biology of non-invasive tumours. She was one of the first to recognise the opportunities from culturing urothelium and subsequently determined the importance of different growth factors and potential modes of various carcinogens. She undertook fine chromosomal mapping in a search for tumour suppressors, when it was a laborious, painstaking task. Her team identified regional losses on Chromosome 8 and the importance of 9p22 and 9p12-13, subsequently shown to be close to the location of the p16 (CDKN2A) locus. Her focus on 9q identified DBCCR1 (the locus for BRINP1) and mutations in the Tuberous Sclerosis gene TSC1. From the disease perspective, Maggie recognised the importance of either FGFR3 or HRAS mutations in the low-grade pathways and in a recent study in non-invasive disease, two genomic subtypes with distinct metabolic profile were identified and a female gender bias in the mutation frequency of the chromatin modifier 
KDM6A was reported. This work rewarded her interest in tumours that are genetically stable and appear lacking in mutations, and points to broader gaps in our biological understanding of cancer.

Maggie originally studied Microbiology at Bristol University, winning the Anna Mayr Harting prize for Bacteriology, before her interest in cancer was fuelled by a $\mathrm{PhD}$ at the Imperial Cancer Research Fund London Research Institute. After working on disease models using rodents and cell culture, she set up her own research group in Leeds. She rose to become Professor of Experimental Cancer Research, Deputy Director of The Leeds Institute of Cancer and Pathology and Head of the Section of Molecular Oncology. Her knowledge and abilities were noticed by a number of journals, including Oncogene for which she became Associate Editor, and numerous others where she was a board member.

Whilst her achievements to biology are well known, Maggie has also fostered a generation of Urologists, kept bladder cancer in the spotlight and contributed enormously to European wide efforts to tackle the disease. Beyond training countless aspiring clinicians and scientists, Maggie has been the 'go to' British Bladder Cancer biologist for journals, books ( $>10$ chapters and 4 editions of an Introduction to the Cellular and Molecular Biology of Cancer), lectures (too many to count) and clinicians (most recently serving on the trial team for Caliber and the Orchid Charity review board). In recognition, she was awarded the St Peter's Medal by the British Association of Urological Surgeons in 2016. We wish her a fantastic retirement, that is well deserved, but she will leave a huge gap.

\section{Dr Rebecca Ross, PhD, University of Leeds, Leeds, UK}

Maggie was my first PI as a PhD student. She set the bar high for my expectations of an outstanding supervisor; to be extremely knowledgeable, confident, straight to the point, but to always be open-minded. Maggie's supportive nature allowed my research skills to flourish. My project management skills were greatly enhanced as Maggie had the keen ability to tighten and loosen the reins when needed. Without Maggie as my $\mathrm{PhD}$ supervisor, along with the group that she developed, I do not think I would be the scientist and the research manager that I am today.

The knowledge that her team, as well as those in collaboration, have contributed to international research is vast. Success within the group was crucial, nevertheless, it was always paramount to smile and be kind and know how to have a good time - I know the latter was key to group success as it was an important question asked by Maggie during our first encounter! I knew from that point that we would get on well!

Maggie became my friend and a strong mentor. I have many happy memories of our working together, and I am glad to say no bad memories (which hearing from others is often the case for PhD supervisors!). I greatly value the hard work that Maggie devoted to myself and many others. Happy retirement Maggie and keep smiling!

All my best, Becky

\section{Dr Nic Munro, PhD, MB BS, Consultant Urologist, Duchy Hospital, Truro, Cornwall, UK}

I came to work in Maggie's Lab as a PhD student in 2000 and was awarded my degree "Proteomic Biomarkers of Bladder Cancer" in 2006.

Maggie was my principal supervisor, it was not a straightforward task: not only did she have to deal with a trainee surgeon but also delve into the unfamiliar world of proteomics!

Other contributors are better placed to describe her significant contribution to the field of bladder cancer science, genetics and chromosome 9 deletions. I recall her exceptional ability to assimilate complex data from several individuals; determine the key issues and ask the pertinent question. There was no point trying to avoid her question or fudge an answer as Maggie would so politely find you out.

Maggie was very caring and looked after me in this new environment. My research project, as is the way, had its ups and downs; throughout all this she remained closely involved and supportive. She is very generous with her valuable time and if she couldn't help, she'd use her international network of friends and colleagues to find someone who could.

Maggie would tell you the truth - my firstborn daughter was introduced to the entire lab team when a week old. She was severely jaundiced but as new parents we couldn't see it. Everyone complimented our beautiful healthy baby until finally Maggie said "she's very lovely but you do know she's bright yellow!" so we took her to our GP. 
I think what was so special was Maggie's ability to lead and inspire. Not only to deliver her own substantial intellectual gifts to science but to nurture and maximise the ability and potential in others. It was a happy, interesting time underpinned by scientific rigor and the pursuit of excellence.

Twenty years later I'm working as a consultant Urologist in Cornwall, the yellow baby is going to medical school and Maggie is retiring. I think my favourite recollection is San Francisco AACR 2002 with Maggie and her team: thoughtful, rigorous science on the podium with raucous pizza and wine to follow.

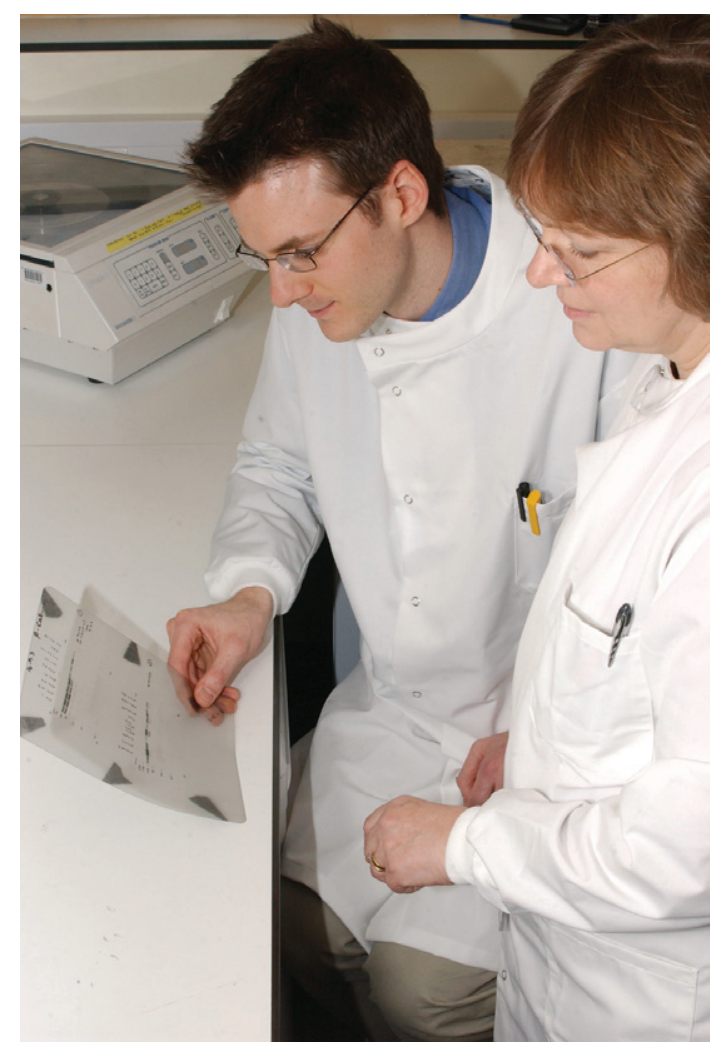

Maggie and urologist James Forster discussing results in the lab at St James's University Hospital, UK (2009). James investigated the expression of NRG1 and its receptors in bladder cancer for his MD.

\section{Richard T Bryan}

The Bladder Cancer Group, Institute of Cancer \& Genomic Sciences, University of Birmingham, UK.

For over 30 years, Maggie has been at the forefront of fundamental bladder cancer research. Her research has elucidated the detailed mutational and copy number landscape of the disease, and the associated cellular responses and pathways. These achievements include:

- The development of novel in vitro models of bladder neoplasia;

- The definition of the mechanistic basis of urothelial transformation;

- The identification of a number of important prognostic molecular markers;

- Chromosome mapping and genomic analysis to identify bladder cancer-associated tumour suppressor genes and oncogenes (including FGFR3, Ras, TERT, RB, FGFR1, STAG2) and their related pathways (including PI3K);

- The definition of the molecular subtypes of bladder cancer.

All of these findings still form the foundations of our understanding of bladder cancer in the deep sequencing era, in which Maggie is an internationally-renowned expert and major contributor - her own research and her nuanced interpretation of that of others has become the benchmark. 
Maggie has always collaborated with clinical urologists such that her research has a translational element in addition to illuminating the fundamental biology of the disease, and numerous urologists as well as basic scientists have completed higher degrees under her supervision. For all of these endeavours, in 2016 she became the very worthy recipient of the British Association of Urological Surgeons' St. Peter's Medal.

I have known of Maggie ever since my PhD days at the start of the millenium. As my own clinical academic career developed, I increasingly interacted with Maggie at conferences or via trial or study management group meetings. Subsequently, as a full time academic, Maggie and I have worked together on several projects and publications, and her advice has always been helpful and insightful. It has been a privilege to have got to know her over these past 20 years, initially through her publications and subsequently through collaboration!

In short, throughout her career, Maggie has been one of the foremost driving forces of molecular-genetic bladder cancer research anywhere in the world.

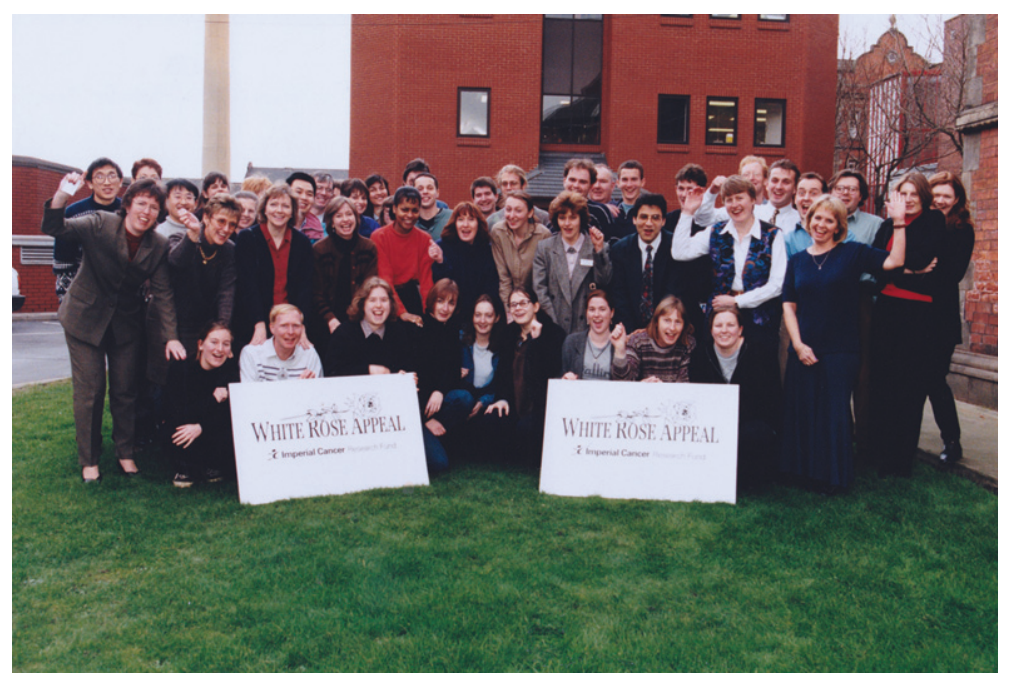

Maggie (second row, 3rd from the left hand side) with researchers from the Imperial Cancer Research Fund Cancer Centre at St James's University Hospital, Leeds, UK (1999).

\section{Dr Erica di Martino, PhD FHEA, Leeds Institute of Health Sciences, University of Leeds, Leeds, UK}

It is a big honour to be invited to contribute to the celebration of Prof. Maggie Knowles's career. I joined Maggie's lab as a junior Postdoc in 2005, immediately after finishing my $\mathrm{PhD}$, and I remained in her group for over 10 years, which is a clear testimony of the fact that it was a great place to work! Maggie managed to create a friendly and supportive environment where everyone was ready to help and no question was too stupid to ask.

During the decade working for Maggie I had two children and felt fully supported in my choice to take a full year off and subsequently return to work part time. When life in academia was still seen by many as a 24/7 vocation, Maggie showed a great understanding of the need for flexible working and career/life balance for her staff. As a woman in science, I have always found it inspirational that Maggie managed to bring up four children of her own and still have a very successful career.

At a time when science is mostly output and impact-driven, one of the things that I enjoyed most when working for Maggie was the relative freedom to let scientific curiosity guide the direction of my research.

I wish Maggie a very happy retirement and thank her for her guidance and support over the years.

Dr Adel Samson, CRUK Clinician Scientist and Honorary Medical Oncology Consultant, Leeds Institute of Medical Research at St James's, University of Leeds, Leeds, UK

I first met Maggie in 2003, when she was assigned to supervise my intercalated Genetics BSc project. As an A-level student and subsequently a young medical student in Leeds, I was interested in genetics, oncology and 
laboratory research. Maggie's laboratory stood out as the perfect environment to undertake my BSc project in cancer genetics. My first meeting with Maggie was in her office, ahead of the commencement of my placement in her group. I was anxious - a young inexperienced amateur facing an internationally renowned Professor of Cancer Genetics. I think that I was the first intercalating medical student to join her group, and naturally, Maggie wanted to know what she had signed up for! I recall being asked three questions; "Have you ever held a Gilson?" I hesitated, then asked "what's a Gilson?". Maggie's eyebrows raised a little. "Do you know the difference between somatic and germline mutations?".... silence.... Maggie's eyebrows raised further. "Do you even know the difference between an oncogene and a tumour suppressor gene?" I knew that one, but I articulated my answer badly. Despite Maggie being very reassuring at the end of our meeting, I was convinced that my career had ended before it even started.

The unintended consequence of my first meeting with Maggie was that I spent 6 months working and studying non-stop in her laboratory. I needed to create a good impression. Maggie was incredibly supportive and she assigned her right-hand scientist, Carolyn Hurst, to supervise me in the laboratory. It paid off, I graduated with a 1st class Genetics degree and a joint-first author paper with Carolyn, in Oncogene. In 6 months, Maggie had enabled my career as an Academic Medical Oncologist. Maggie remained an invaluable mentor for the next 16 years and was instrumental in enabling me to launch my own laboratory group and to win a recent Clinician Scientist award. Enjoy your retirement Maggie; you are forever in my heart and I will always be indebted to you, Adel

\section{Dr. Kerstin Junker, Chief of the EAU section of urological research (ESUR)}

The EAU Section of Urological Research (ESUR) aims to promote basic and clinical research in the field of urology and related areas. We act as a platform for researchers in different disciplines, in order to stimulate coordination and exchange of experimental research. Before becoming an EAU Section in 2010, the ESUR acted as an independent body as the European Society for Urological Research. At this time, Maggie was selected as a board member of the ESUR in 2009 as an expert in bladder cancer research. Up to that time, ESUR was mainly focused on prostate cancer, and therefore, the society intended to involve more researchers from other fields in urology. To tell a small anecdote: I had been proposed as a board member to represent kidney cancer in 2009. Nevertheless, and not surprising, Maggie received much more votes, which did not disappoint me. I felt even honored being a candidate in parallel with Maggie. At this time, I knew Maggie from many papers as an outstanding expert in bladder cancer research. In a fascinating and a very didactic way, she explained molecular principles of bladder cancer. In the following years, I was deeply impressed to meet her personally and to work together within the ESUR framework.

During her board membership, Maggie actively structured our section as well as our annual meetings. Thus, she was a member of the scientific committee several times and suggested interesting topics and speakers. There was an intensive commitment concerning cooperation with our sister organization SBUR in the U.S. She was invited to give talks at the joint ESUR-SBUR meetings not only as a specialist in bladder cancer but also as an ESUR representative.

As an EAU section, we are more actively involved in the EAU annual meeting. Here, she reviewed submitted abstracts and chaired poster sessions on bladder cancer research for many years.

I met Maggie several times at the AACR meetings. Ellen Zwarthoff had invited me to share their dinner in Anaheim, California. During the following years, it always was a pleasure to meet such outstanding women researchers who like good wine and food as I do.

Needless to say that Maggie always was a committed European. But she always did it her way and she always found a good way.

Seth P. Lerner, MD, Beth and Dave Swalm Chair in Urologic Oncology, Director of Urologic Oncology, Baylor College of Medicine, Houston, TX, USA

I first became aware of Maggie's research when I was a fellow in Peter Jones lab at USC in 1990. I was working on Chromosome 9 alterations and learned about her important work in this area. Peter had left for the UK for a year-long sabbatical and Maggie had become a mentor from afar and we have kept our kinship alive ever since. 
Maggie has been a force in bladder cancer translational research her entire career and was always the first scientist we turned to when planning bladder cancer meetings. She has been a tireless investigator and supporter of all bladder cancer related causes. She embraced the idea of our multi-disciplinary clinical and research meetings supporting the Bladder Cancer Advocacy Network Think Tank, Society of Urologic Oncology and many others with her attendance and sharing her latest research results. More recently our scientific paths have intersected between the TCGA and work she and Carolyn Hurst published further elucidating the molecular underpinnings of early stage bladder cancer. Maggie, congratulations on a brilliant career. Your tireless work and devotion to doing science the right way has shone a brilliant light on the molecular underpinnings and biology of early stage bladder cancer that will serve as a beacon to all who carry on in this important field of translational research. I am most grateful for your guidance and your friendship over the last 30 years.

My very best,

Seth Lerner

Baylor College of Medicine

Dan Theodorescu, MD PhD, Director of Samuel Oschin Comprehensive Cancer Institute, Los Angeles, CA, USA

When deciding on a lab to go to for my $\mathrm{PhD}$, I interviewed with several lab directors and asked them all if they would, in addition to my thesis project, allow me to "dabble" in an area that I was interested in which was bladder cancer. I ended up working on bladder cancer during my $\mathrm{PhD}$ and in fact, my first paper as a graduate student was on this topic. As I was preparing to work on this topic, I read as much as I could about bladder cancer biology and one name kept popping up ... Knowles MA ... Little did I know at that time that Margaret A. Knowles had already worked and made seminal contributions in collaboration with some of the leading cancer biologists and bladder cancer scientists of that era, L. M. Franks and Marion Hicks, and was going to become herself a leading figure in the bladder cancer field. One of my favorite papers then and still now, described multistage transformation of cultured rat urothelium (Methods Cell Biol 1980;21B:257-85). I was very fortunate that during my PhD studies I had the opportunity to go to several AACR meetings and at one of them, I believe 1992, I finally met Maggie. I had been looking forward to meeting her for years and I still remember that she was very excited at the time to transition from cell biology and carcinogenesis to more molecular studies of this process focusing on $\mathrm{Rb}$ and $\mathrm{H}$-Ras. The theme of molecular changes in carcinogenesis has of course been a sustaining one throughout her illustrious and prolific career. Since our first meeting, I have interacted with Maggie countless times and enjoyed every minute. Her gracious and generous nature, her wit, scientific insights and her good humor have always been her calling card and has made her one of my favorite teachers, colleagues and friends over the past $25+$ years. With much appreciation and admiration for all you have done for our field.

On behalf of the Bladder Cancer Journal and all its editors and staff, I would like to extend my thanks to Ellen Zwarthoff and Carolyn Hurst to compiling and editing this wonderful tribute to Maggie.

\section{CONFLICTS OF INTEREST}

JWFC: has received reimbursement for consultancy from Astra Zeneca, Roche and Janssen, speaker fees from BMS, MSD, Nucleix and Roche, and honoraria for membership of an advisory board for Ferring. JWFC is funded by an NIHR Research Professorship

RTB: has contributed to advisory boards for Olympus Medical Systems \& Janssen, and undertakes research funded by UroGen Pharma and QED Therapeutics

SPL: Advisory Board: FerGene, Pfizer

Consultant: Genentech, UroGen, Vaxiion, Merck, QED Therapeutics, Verity

Clinical Trials: Genentech (SWOG), UroGen, Vaxiion, Endo, FKD, JBL (SWOG), Viventia

Licenses/Patents: TCGA Classifier

Other: UroToday (honoraria), IOS Press (editorial responsibilities, compensated), co-editor bladder cancer section UpToDate 
DT: Consultant: Machavert, Merck, Urogen

Honoraria: Machavert, Merck, Urogen

Licenses/Patents: University of Colorado

Research Support: Medivation/Astellas

Stockholder in: Aurora Oncology, PrecisionProfile

Other: IOS Press (editorial responsibilities, compensated)

EZ,TB,PS,CH,DT,EC,JR,NM.EdM,AS and KJ: no relevant conflicts of interest 